\title{
ИНСТИТУЦИОНАЛЬНАЯ ТЕОРИЯ ФОРМИРОВАНИЯ НАЦИОНАЛЬНОГО БОГАТСТВА: КОНЦЕПЦИЯ МЕНЕДЖМЕНТА
}

\author{
(c) 2021 Демина Надежда Константиновна \\ кандидат экономических наук \\ Южно-Уральский государственный университет \\ (Национальный Исследовательский Университет), Россия, Челябинск \\ E-mail:deminank@susu.ru \\ (c) 2021 Попова Елена Александровна \\ доктор экономических наук, доцент \\ Южно-Уральский государственный университет \\ (Национальный Исследовательский Университет), Россия, Челябинск \\ E-mail: 73519045153@yandex.ru \\ (c) 2021 Базелюк Владимир Васильевич \\ доктор педагогических наук \\ Южно-Уральский государственный университет \\ (Национальный Исследовательский Университет), Россия, Челябинск \\ E-mail:bazeliukvv@susu.ru \\ (c) 2021 Романова Анна Валентиновна \\ кандидат педагогических наук \\ Южно-Уральский государственный университет \\ (Национальный Исследовательский Университет), Россия, Челябинск \\ E-mail:romanovaav@susu.ru
}

Обоснован генезис экономической теории как науки о богатстве и государственном управлении. Особое внимание уделено институциональной направленности развития теории общественного воспроизводства национального богатства и обоснованию роли экономических институтов в его формировании.

Ключевые слова: национальное богатство, институциональная теория, генезис, менеджмент, формирование, источники богатства, развитие.

Введение. Концепция менеджмента является базовой для определения современной тенденции развития как частного, так и общественного сектора экономики. В представленной работе осуществлен поиск возможностей применения принципа синергизма менеджмента в исследовании источников расширенного воспроизводства национального богатства.

Основоположник кембриджской школы экономической науки А.Маршалл в предмет экономических исследований включал поиск источников национального богатства и мотивы действий экономических субъектов, на современном этапе развития науки акцент смещен на исследование особенностей формирования человеческого капитала как основополагающего фактора развития экономики.

Рост профессионализма менеджмента все более превращает его в самостоятельную силу «когнитариат» (социальную группу, чья мощь основывается на знании, на знании о знаниях как «делать» деньги, увеличивать доход, прибыль), а это - по сути - и есть процесс формирования национального богатства.

Рост богатства связан с превышением стоимости созданного продукта над расходами на привлеченные ресурсы (формирование прибавочной стоимости). Поиск решений проблемы соотношения объема располагаемых ресурсов и предъявляемыми потребностями лежит в основе экономической науки.

Развитие науки позволило сформировать достаточную базу для появления направлений экономической мысли, связанных с систематизацией знаний о методах управленческой деятельности. Как справедливо пишет Г.Бойль, 
встарь богатейшими странами были те, природа которых была наиболее обильна; ныне богатейшие страны те, в которых человек наиболее деятелен. Именно в данной концепции нами рассматривается теория формирования национального богатства исходя из менеджерского подхода.

Результаты исследования определены следующими позициями: 1) генезис экономической теории как науки о богатстве; 2) институциональная оценка экономического пространства богатства; 3) институциональная направленность развития теории общественного воспроизводства национального богатства; 4) обоснование роли экономических институтов в формировании национального богатства; 5) институциональная оценка развития концепции государственного менеджеризма.

1. Генезис экономической теории как науки о богатстве

На первоначальном этапе в становлении науки о богатстве можно выделить такие концепции как меркантилизм, теоретическое учение физиократов и классическая школа.

Все они, так или иначе, затрагивают две проблемы - природу происхождения предпринимательского дохода и роль государства в росте национального богатства.

Базовой позицией классической школы является теория доходов, получаемых основными классами общества. В качестве источника дохода рассматривалась оплата привлекаемого ресурса: земельная рента, предпринимательская прибыль и заработная плата рабочих. «При обмене готового товара на деньги,- писал А. Смит,- помимо оплаты цены материалов и заработной платы работников, должна быть еще дана некоторая сумма для прибыли предпринимателя, рискующего своим капиталом в этом деле. Поэтому стоимость, которую рабочие прибавляют к стоимости материалов, распадается сама в этом случае на две части, из которых одна идет на оплату их заработной платы, а другая на оплату прибыли их предпринимателя на весь капитал, который он авансировал в виде материалов и заработной платы» [9]. Кроме того, на присвоение части стоимости (ренты) претендует землевладелец. «Эта рента образует третью составную часть цены большей части товаров». Оплата вклада предпринимательского капитала рассматривалась учеными-классиками как один из параметров трудового ресурса.
Интерес в этом плане представляют идеи Д.Рикардо о роли труда в формировании стоимости товаров [8]. По его мнению, реальная цена производства включает в себя затраты не только живого, но и овеществленного труда. Данная идея в дальнейшем вошла в науку в качестве учета элемента «амортизации» в расчете производственных издержек.

Классическое направление экономической науки развивалось в направлении решения двух важнейших - с позиций вошедших в ее историю представителей - вопросов: 1) обеспечение оптимальной пропорции при распределении продукта между факторами производства; 2) оценка роли общества в формировании национального богатства.

Впервые вопрос был поднят Дж. Б. Кларком в работе «Распределение богатства» [1]. В ней он сформулировал теорию предельной производительности, согласно которой в процессе производства наблюдается убывающая производительность капитала и труда (при постоянной численности работников с определенного момента дополнительная единица капиталовложений характеризуется меньшим приращением объема выпуска; при неизменном капитале наступает этап снижения средней и предельной производительности трудового ресурса). В рамках маржиналистской теории обосновывается формирование оплаты труда на основе производительности «предельного рабочего».

Дж.Б.Кларк был представителем «ортодоксальной неоклассической теории», которую можно считать альтернативой марксизму (теории прибавочной стоимости К. Маркса, представляющей собой модернизированную теорию доходов А. Смита - Д. Рикардо).

В числе первых сложилась австрийская школа маржинализма, представителями которой была предложена «психологическая теория процента», объяснявшая происхождение прибыли и заработной платы. В соответствии с ней человеку свойственно оценивать блага настоящего выше, чем блага будущего, продукт при этом относился к первому, а труд - ко второму виду благ. Разница в оценках составляла процент или прибыль капитала. Рабочие же при этом получали зарплату за свой труд (то есть за благо будущего).

В экономической теории постоянно шел поиск «золотой середины» в вопросах доходов общественного сектора, обеспечиваемых на- 
логообложением. При этом в трудах экономистов отмечалось, что данные потоки должны составлять содержание совместной работы правительства, профсоюзов и объединений предпринимателей. Современные авторы развивают исследование в данном направлении научного поиска [10].

В рамках генезиса экономической науки как науки о богатстве стоит отметить исследование роли общества в формировании национального дохода. В историю науки вошли идеи Д. М. Кейнса, который первым бросил вызов неоклассике, разработав программу регулирования рыночной экономики, нацеленную на борьбу с безработицей. Суть идей Кейса состояла в искусственном стимулировании занятости, нацеленном на расширении потребительского спроса и запуске мультипликативного эффекта расходов приводящего к росту национального дохода.

Интерес представляет - с позиции рассматриваемого вопроса - и монетаристская школа economics во главе с М.Фридманом. Именно она после резкого удорожания энергоресурсов в 1970-е годы заняла лидирующие позиции в рамках теоретических вопросов роста национального богатства.

2. Институциональная оценка экономического пространства богатства

Данная оценка определяет богатство как совокупность возможностей осуществлять производственную деятельность, а также деятельность в сфере потребления конкретных ценностей. В соответствии с данной оценкой, богатство есть энергия, определяющая суть любой производительной работы. Последняя рассматривается с позиций справедливости, свободы и силы воли субъектов экономических отношений.

Институциональная оценка социокультурного пространства богатства представлена в таблице 1. В качестве элементов системы выделены деньги, менталитет и экономический аспект богатства на микро- и макроуровне.

В экономических учениях XX века все большая роль отводится изучению такого источника богатства как человеческий капитал, концепция менеджмента, заложенная в основу поиска факторов развития, раскрывается в рамках подобных направлений экономических исследований.

В этом плане интерес представляет алгоритм овладения богатством, разработанный Н.Хиллом, который можно представить в виде логической цепочки: чувства - мысли - действия. Под богатством понимается в данном случае оплата труда менеджеров, а также их чувства, мысли и действия в сфере управленческого труда.

\section{3. Институциональная направленность} развития теории общественного воспроизводства национального богатства

В современных условиях лидирующие позиции в рассматриваемом нами вопросе занимает институциональная экономическая теория. Ключевым понятием при этом является «институт», а именно соответствующие механизмы и правила поведения экономических агентов (с позиций их взаимодействия в экономическом пространстве богатства).

Институты задают общие рамки взаимодействия индивидов и фирм, определяемые правилами их поведения на рынке [10]. Конкретные же рамки взаимодействия, описывающие условия совершения сделок, определены положениями контракта (договора) между непосредственны-

Таблица 1. Основные параметры социокультурного пространства богатства

\begin{tabular}{|l|l|}
\hline \multicolumn{1}{|c|}{ Параметр } & \multicolumn{1}{|c|}{ Содержательный аспект } \\
\hline 1. Деньги & $\begin{array}{l}\text { Носители прав собственности. Участники экономических отношений конкретных } \\
\text { субъектов. Наличие возможностей, реализуемых в процессе производства или } \\
\text { потребления представителей богатства, его распределения и реализации на прак- } \\
\text { тике. Способность обращения в реальное богатство. Понятие ценности данного } \\
\text { богатства и формы будущего (в рамках мыслительной функции человека) }\end{array}$ \\
\hline $\begin{array}{l}\text { 2. Экономический } \\
\text { аспект богатства }\end{array}$ & $\begin{array}{l}\text { Форма экономического пространства производительной деятельности челове- } \\
\text { ка. Определенный образ существования и определенный образ деятельности. } \\
\text { Проявление силы воли человека. Экономический потенциал индивида и образа } \\
\text { его жизни и внутренней свободы. Составная часть совокупного экономическо- } \\
\text { го потенциала (экономических активов). Национальный доход и богатство, его } \\
\text { воспроизводство }\end{array}$ \\
\hline $\begin{array}{l}\text { 3. Менталитет в отноше-- } \\
\text { нии богатства }\end{array}$ & $\begin{array}{l}\text { Особенности русской истории, культуры и политики. Ресурсная оценка богатства. } \\
\text { ния менталалитета россиян. Отношение к культу богатства. Гарантии и уверенность } \\
\text { в завтрашнем дне }\end{array}$ \\
\hline
\end{tabular}


ми участниками взаимодействия в рамках предпринимательского менеджмента [7]. Данное (последнее) понятие объединяет воедино индивидов и фирмы в соответствии со следующим алгоритмом: институты - правила поведения экономических агентов - предпринимательский менеджмент, объединяющий между собой фирмы и индивиды - оценка и формирование богатства (индивидуального, коллективного, национального).

Помимо рассмотрения национальной экономики как совокупности институтов, возможно изучать ее с позиции деятельности экономических агентов. Именно они являются основой в анализе предпринимательского менеджмента.

В современной научной литературе менеджмент часто рассматривают как систему, позволяющую снижать трансакционные издержки, и создавать парадигму предпринимательской культуры.

Экономические агенты, осуществляющие деятельность в рамках существующей системы, действуют в соответствии с нормами как «базовым элементов института рынка».

4. Обоснование роли экономических институтов в формировании национального богатства

Обратим далее внимание на обоснование роли экономических институтов в формировании национального богатства (и роли в этом системы менеджмента хозяйствующего субъекта). Обоснование данной роли связано с трансакционными издержками хозяйствующего субъекта. А эти издержки, в свою очередь, являются важной составной частью институционального направления экономической теории [2].

Трансакционные издержки можно подразделить на внутренние и внешние по отношению к фирме. Общий вид издержек при этом можно представить следующим образом (рисунок 1).

Снижение данного вида издержек всецело определяется деятельностью менеджеров хозяйствующего субъекта (это своего рода их вклад в рост доходов на микроуровне и национального богатства - на макроуровне). Речь прежде всего идет о творческом поиске новых решений в сфере практики управления и обновления методологического инструментария менеджмента [6].

Менеджмент справедливо называют «когнитариатом», который оценивается синергетическим эффектом, величиной последнего [1]. В этом плане интерес представляет и мнение Н. Сурниной о том, что фирма, оптимизирующая этот эффект тщательным отбором товаров и рынков, обладает высокой гибкостью в выборе конкурентной позиции.

Фирма, исходя из отмеченного, является самоорганизующейся экономической системой. В ее основе лежит не только предпринимательская, но и инновационная деятельность. И в этом плане можно вести речь о «синергизме менеджмента», определяющем органическую связь экономики микро- и макроуровня (в рамках формирования национального богатства).

5. Институциональная оценка богатства культуры государственного менеджеризма

Суть данного направления институционального исследования богатства можно сформулировать как совокупность концептуальных подходов, представленных в таблице 2.

Концепция менеджмента в рамках государственного управления на уровне региона позволяет применять методы стратегического планирования и мониторинга реализации программ, направленных на стимулирование спроса и роста регионального продукта.

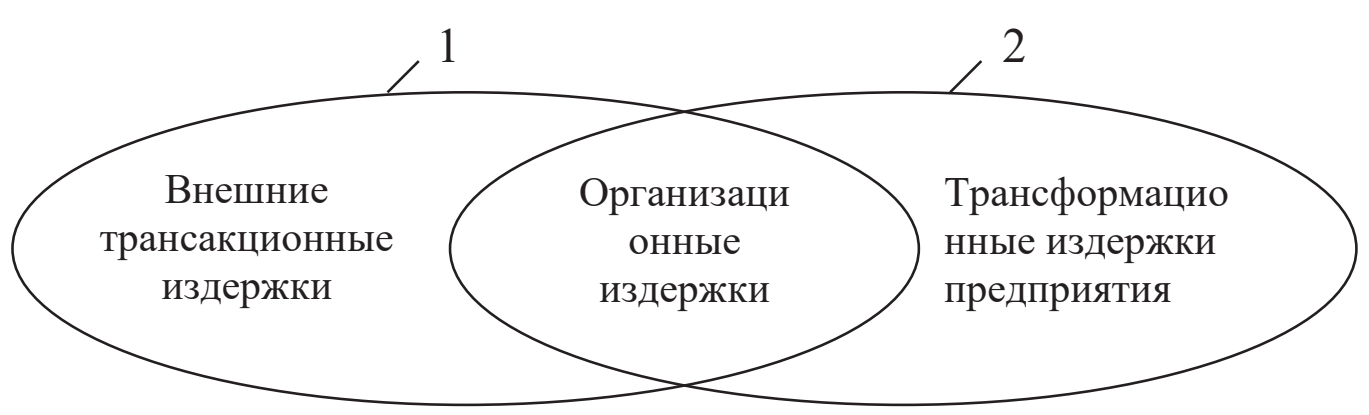

Рисунок 1. Трансакционные издержки хозяйствующего субъекта:

1 - общие трансформационные издержки; 2 - внутренние издержки субъекта, осуществляющего предпринимательскую деятельность 
Таблица 2. Основополагающие параметры государственного менеджеризма

\begin{tabular}{|l|l|}
\hline \multicolumn{1}{|c|}{ Параметр } & \multicolumn{1}{|c|}{ Содержательный аспект } \\
\hline $\begin{array}{l}\text { 1. Маркетинговый менед- } \\
\text { жеризм }\end{array}$ & $\begin{array}{l}\text { Сфера услуг. Защита государства от иностранной конкуренции. Выставочно- } \\
\text { ярмарочная деятельность. Моделирование деятельности выставочных центров. } \\
\text { Формирование материально-технической базы (инфраструктуры). Особенно- } \\
\text { сти менеджеризма в рамках крупных промышленных и административных } \\
\text { центров (Екатеринбург, Уфа, Челябинск и др.) }\end{array}$ \\
\hline $\begin{array}{l}\text { 2. Институциональная кон- } \\
\text { цепция государственного } \\
\text { менжеризма }\end{array}$ & $\begin{array}{l}\text { Аллокационная функция государственного регулирования предприниматель- } \\
\text { ской деятельности. Прямое участие государства в размещении и перераспре- } \\
\text { делении ресурсов в условиях, вызывающих необходимость компенсировать } \\
\text { хронические недостатки рыночной экономики. Воздействие государства на } \\
\text { указанные процессы тем значительнее, чем более неопределенным для хозяй- } \\
\text { ствующих субъектов является состояние внешней среды }\end{array}$ \\
\hline $\begin{array}{l}\text { 3. Культура государствен- } \\
\text { ного менеджеризма }\end{array}$ & $\begin{array}{l}\text { Основные блоки формирования категории: методологические основы дове- } \\
\text { рительность отношений, организационный аспект, регулирование культуры } \\
\text { регионального маркетинга, оценка культуры. Социокультурный аспект го- } \\
\text { сударственного менеджеризма как высшее проявление профессиональной } \\
\text { компетентности в сфере регионального маркетинга }\end{array}$ \\
\hline
\end{tabular}

Многовековой опыт развития технологий бизнес-процессов в различных отраслях экономики позволяет внедрять прорывные идеи расширения рынков и роста стоимости капитала в долгосрочном периоде. Современные исследования институциональной структуры экономики направлены на внедрение концепций менеджмента в систему управления элементами общественного сектора, такими как маркетинг услуг бюджетных организаций, стратегический аудит реализации государственных и муниципальных программ.

\section{Заключение}

1. Генезис экономической теории как науки о богатстве определяется становлением ряда школ, представителями которых являются А. Смит, Д. Рикардо, Т. Манн, Дж. Кларк (представитель ортодоксальной неоклассической теории). Существенный вклад внес Ф. Лист (космополитическая экономия), О.Шпак (концепция универсализма). Альтернативный взгляд на роль государства в развитии экономики берет начало в работах Д.Кейнса и М.Фридмана. Вопросы факторов создания добавочной стоимости находят отражения в трудах представителей австралийской школы маржинализма.

2. В работе особое внимание уделяется институциональному направлению развития теории общественного воспроизводства наци- онального богатства. Категорийный аппарат в этом плане включает в себя: трансакционные издержки экономических агентов, правила их поведения, контракты (имплицитные и др.), институты, к числу которых относятся и фирмы, деятельность которых определяется менеджментом.

3. Обоснованию их роли в формировании национального богатства посвящен заключительный раздел работы. Акцент в нем делается на синергизме менеджмента и его роли во взаимосвязи экономики микро- и макроуровня (в рамках формирования национального богатства).

4. В работе обоснован алгоритм исследования феномена богатства, а именно: обоснование экономической теории как науки о богатстве; Методология исследования феномена богатства и его сущности; субъекты образования богатства и уровни его оценки. Авторами актуализируется в этом плане микроуровень, определяемый менеджментом фирмы (хозяйствующего субъекта).

5. Заключая, отметим также, что следует указать на противостояние двух базовых моделей, объясняющих рост национального богатства,- патерналистской и либеральной. Нахождение компромисса в этом плане (исходя из менеджерского подхода с учетом национальных особенностей) нацелено на поиск источников роста.

\section{Библиографический список}

1. Богатство как менталитет и творчество экономического разума / А. Е. Кенжибаев, И. В. Лавров, А. Н. Попов.Екатеринбург: УрГЭУ, 2003.- 144 с.

2. Бьюкенен, Дж. Избранные труды / Дж. Бьюкенен // Нобелевские лауреаты. Т.1.- М.: Таурус Альфа, 1997. - С. 23-84. 
3. Дементьев, Г. М. Синергизм менеджмента как современная основа формирования национального богатства / Г. М.Дементьев.- Челябинск: УралГУФК, 2009.-264 с.

4. Кларк, Дж. Распределение богатства. Пер. с англ. / Дж. Кларк.- М.: Альфа, 2000. - 216 с.

5. Попова, Е.А.Контрактная парадигма формирования национального богатства / Е.А.Попова, И.В.Лавров, Г.М.Дементьев.-М.: ВНИЭТУСХ, 2004.-144 с.

6. Попов, А.Н. Менеджмент как когнитариат и основа формирования национального богатства / А.Н.Попов, Г. М.Дементьев.- Челябинск: УралГУФК, 2007.- 64 с.

7. Попов, А.Н. Менеджмент в системе коллективного предпринимательства и формирования национального богатства / А. Н. Попов, Ю. Д.Доронин, Г. М. Дементьев.- Челябинск: УралГУФК, 2008. - 96 с.

8. Рикардо, Д. Начала политической экономии и налогового обложения. Пер. с англ. / Д. Рикардо.- М.: Экономика, 1987.- 460 с.

9. Смит, А. Теория нравственных чувств. Пер. с англ. / А. Смит.- М.: Экономика, 1997. 318 с.

10. Соперничество теорий как основа генезиса политической экономии / В. Л. Берсенев, А. И. Татаркин, А. Г. Шеломенцев.-Екатеринбург: Институт экономики УрО РАН, 2005.-81 с. 